\title{
Design and Implementation of the Recording Processing Supporting System using RFID
}

\author{
Mi-Hye Baek, Bong-Gi Kim, and Hyun-Ju Kim, Member, KIICE
}

\begin{abstract}
RFID technology is one of the verification technology that use radio frequency. Use and study of RFID are on the increase because RFID is a one of main technologies in ubiquitous. In this paper, we address to develop a Record Processing System using RFID. The purpose of this paper is improvement of accuracy and efficiency on Record Processing System by applying RFID. Later, this paper will be able to help to establish of u-Campus.
\end{abstract}

Index Terms- RFID Reader API, RFID Middleware, EPCIS, RFID Network

\section{INTRODUCTION}

WE are currently heading toward a ubiquitous society where information is communicated in real time. With the addition of location recognition, the information society in which we live is becoming intelligent and connected by networks, anytime and anywhere. Radio Frequency Identification (RFID), an automatic recognition technology, is regarded as key in achieving a ubiquitous society[1]. RFID technology involves the use of a tag containing object information attached to an object. Object information is retrieved by radio frequency to serve a user[2].

This study is organized as follows. Chapter 2, Related Studies, deals with knowledge necessary for the realization of an RFID system, focusing on middleware. Chapter 3 describes RFID-based system design and composition to support automatic recordation of student attendance, showing the system's diagram and components and illustrating them with a scenario. Chapter 4 examines a real setting environment and the experimental results. Finally, Chapter 5 provides conclusions and suggests objectives for future studies.

\section{RELATED STUDIES}

\section{1) RFID Reader API}

The RFID reader API (Application Program Interface) is a language or a library in the form of messages to be used for communication between the RFID reader and an

\footnotetext{
Manuscript received September 21, 2011; revised November 18, 2011; accepted November 30, 2011.

Bong-Gi Kim(Corresponding Author) is with the Department of Computer Convergence Engineering, GNTECH, Jinju, 660-758, Korea (Email: bgkim@gntech.ac.kr)
}

application program or between upper-level systems[3].

\section{2) RFID Middleware}

RFID middleware exists between the reader and the upper-level system to overcome inoperability between disparate RFID reader systems and to enable en bloc communication with the upper-level system.

Middleware is software that supports and manages the reader and gathers and filters data from the disparate readers to send them to the application system[4].

\section{3) EPCIS}

Electronic Product Code Information Services (EPCIS) is a business standard interface for sharing EPC data and information among businesses that are gathered using RFID. Past to present product information from EPCIS data is captured, managed, and provided in Physical Markup Language (PML), if requested or queried, for the production of the information[5].

\section{4) RFID Network}

An RFID network is a directory system to pool information for the management of an RFID system, providing the necessary service using a business's own information server. Using an RFID network, the memory limitations of an RFID tag can be overcome and economic, fast, and real-time recordation of information is possible[6].

\section{RFID-BASED DESIGN OF GRADE PROCESSING SYSTEM PROVIDING AUTOMATIC RECORDATION OF ATTENDANCE}

\section{1) Diagram and Operation of the Suggested System}

This study adapted the existing RFID staff management and gate monitoring system to a school system for the purpose of student management, attendance recordation, and grade management. The design of the system consists of an RFID component to process RFID attendance and an application processing component to process grades after receiving attendance information.

The RFID system consists of an RFID tag and reader, middleware and application program, and a server. Figure 1 is a diagram showing the suggested grade processing application system using RFID attendance. 


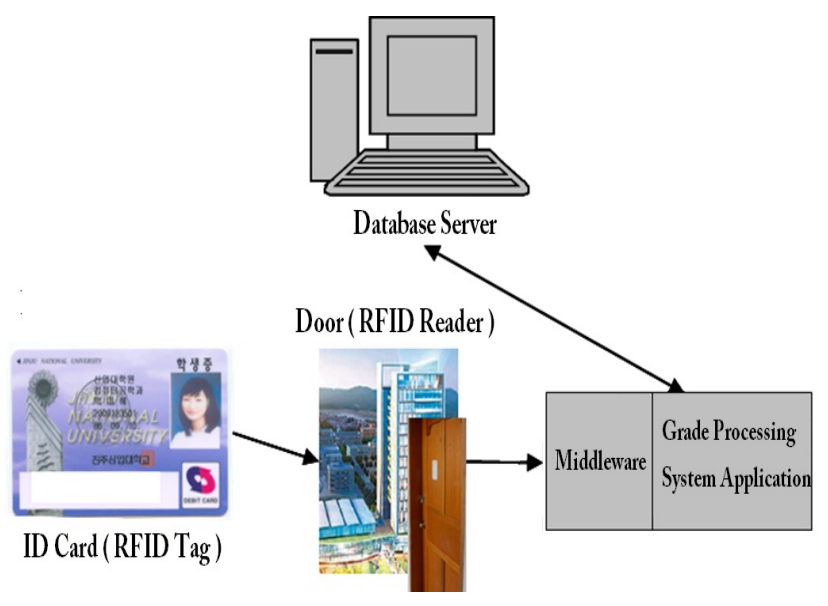

Fig. 1. Configurations of Record Management System

\section{2) Database Design and ER Diagram}

The database is comprised of student, class, professor, grade, and attendance tables. The tag contains personal information about the students in the table. Attendance table is recorded when the reader retrieves tag information, and the grade management system uses all the tables.

Figure 2 shows the suggested system's five database tables: class, professor, grade, attendance, and year of the class tables. Figure 3 shows a table's ER diagram indicating the relationships between the tables.

Figure 4 shows the data flow; a tag recognizes student information once a student enters and records attendance information to the database so that an administrator can check and manage the status and the professor can process grades after logging on to the grade processing system.

\begin{tabular}{|c|c|c|}
\hline \multicolumn{3}{|c|}{ Class Table } \\
\hline Column Name & Data Type & Allow Nulls \\
\hline 18 LectureNumber & int & 四 \\
\hline \multirow{2}{*}{$\begin{array}{l}\text { LectureName } \\
\text { ProfessorNumber }\end{array}$} & Char $(20)$ & 『 \\
\hline & int & 曰 \\
\hline Lectureclass & char $(20)$ & 甲 \\
\hline Lecturepoint & int & v \\
\hline \multirow[t]{2}{*}{ Completionclass } & char (20) & $\nabla$ \\
\hline & & 曰 \\
\hline \multicolumn{3}{|c|}{ Student } \\
\hline Column Name & Dita Type & Allow Nulls \\
\hline Dis StudentNumber & int & 口 \\
\hline StudentName & char(10) & 目 \\
\hline Grade & int & च \\
\hline Major & char(20) & 目 \\
\hline \multicolumn{3}{|c|}{ Attemdamce Table } \\
\hline Column Name & Dato Iype & Allow Nulls \\
\hline 18 LectureNumber & int & U \\
\hline 8 studentNumber & int & $\Delta$ \\
\hline 8 week & int & $\square$ \\
\hline Attendance & int & 『 \\
\hline
\end{tabular}

\begin{tabular}{|c|c|c|}
\hline \multicolumn{3}{|c|}{ Professor Table } \\
\hline Column Name & Oato Type & Allow Nulls \\
\hline Di Pidessarinumber & int & ( \\
\hline Pridessonliame & char(10) & 目 \\
\hline Major & chror(20) & 目 \\
\hline & & 田 \\
\hline
\end{tabular}

\begin{tabular}{|c|c|c|}
\hline \multicolumn{3}{|c|}{ Grade Table } \\
\hline Column Name & Data Iype & Allow Nulls \\
\hline \begin{tabular}{|l|l|l}
$n$ & LectureNumber
\end{tabular} & int & 맘 \\
\hline 8 Student Number & int & ט \\
\hline Middeleramine & int & $\nabla$ \\
\hline EndExamine & int & $\nabla$ \\
\hline Repot & int & च \\
\hline Attitude & int & $\nabla$ \\
\hline Attendance & int & $\nabla$ \\
\hline Others & int & $\nabla$ \\
\hline TotallectureTime & int & $\nabla$ \\
\hline Totalof Marks & int & $\nabla$ \\
\hline Grade & chartio? & $\nabla$ \\
\hline & & $\square$ \\
\hline
\end{tabular}

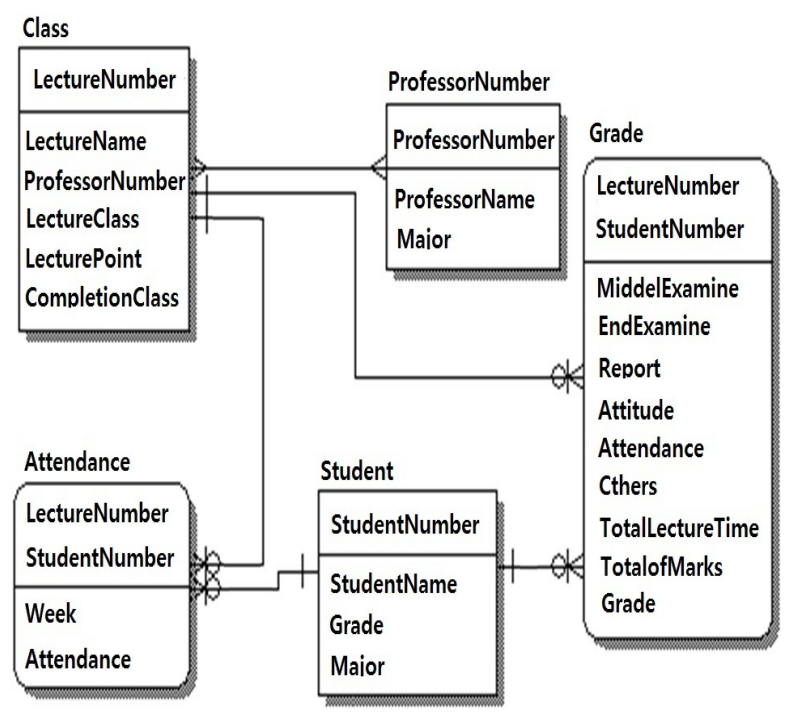

Fig. 3. ER-Diagram of Record Management System

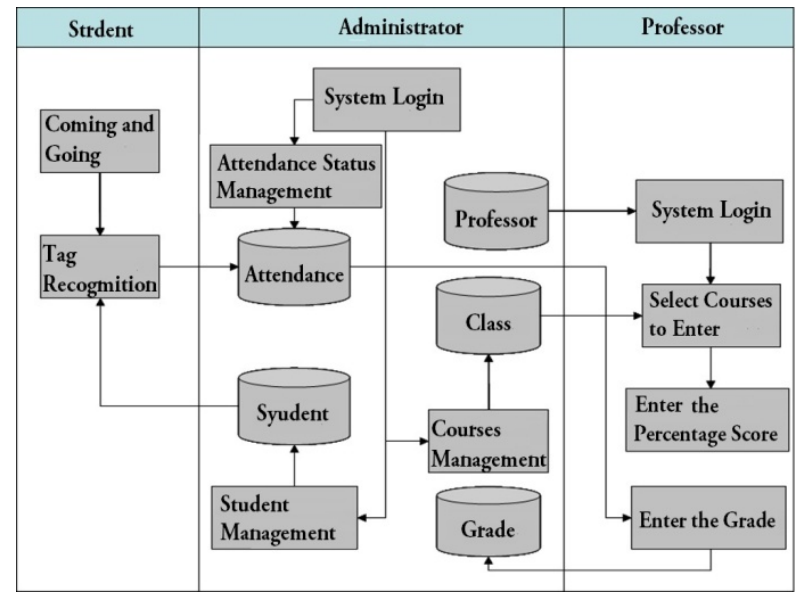

Fig. 4. Data Flow Chart of System

\section{Experiments and Implications}

\section{1) Development Environment}

The system in this study consists of hardware, communication modules, and a grade processor. For the hardware, an RFID module of HBE-RFID-REX equipment manufactured by Hanbag Electronics and a $125 \mathrm{KHz}$ tag were used. For the devices, ATmega128 was used for the $\mathrm{CPU}$, and as program languages, $\mathrm{C}++$ was used for the reader and tag connection and Visual Basic 2010's WPF based C\# was used for the grade processing system.

Fig. 2. Database Table 


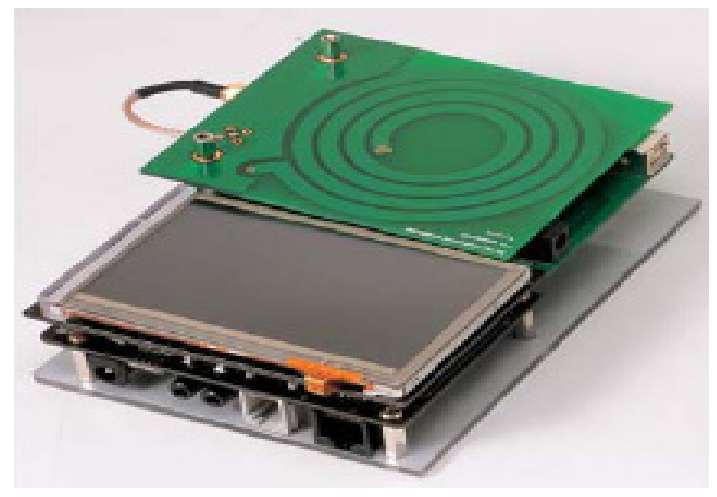

Fig. 5. Used Reader

\section{2) Simulation}

The suggested system consists of the recognition component of the reader and a grade processing component based on the recognized information. The tag recognition component of the reader is an RFID processing module to recognize tagged ID cards - it recognizes the identification number in a student ID from the RFID reader to process a hardware tag.

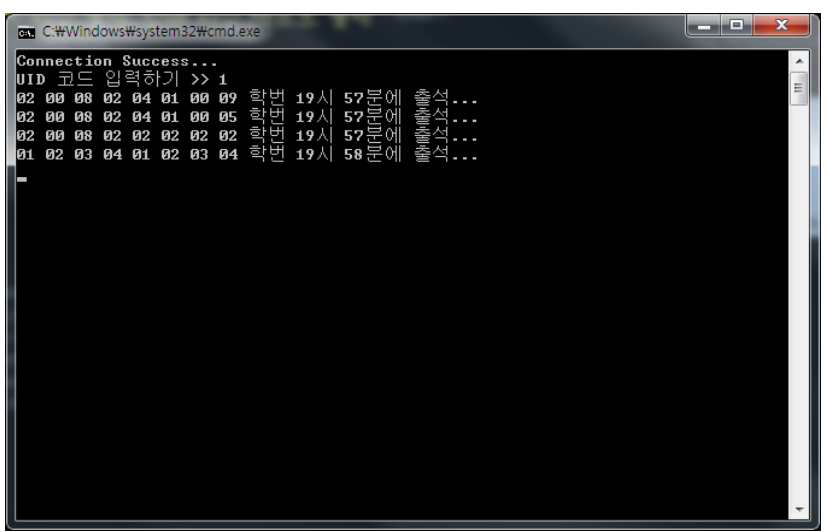

Fig. 6. Tag recognition

Figure 6 shows the reader recognizing tag information. It illustrates the attendance of four students.

An administrator inputs a password into the password section and can add or delete classes and manage students, as in Figures 8. He can also check and manage attendance information, as in Figure 9. Figure 10 is automatically recorded by Figure 6's tag recognition.

Figure 11 shows a client user screen. After a professor has logged on using his code, the attendance grade is calculated from the attendance information retrieved from the server and the final grade is calculated after grade processing ratios suitable for evaluation rate, assignment grades, and exam grades are inputted.

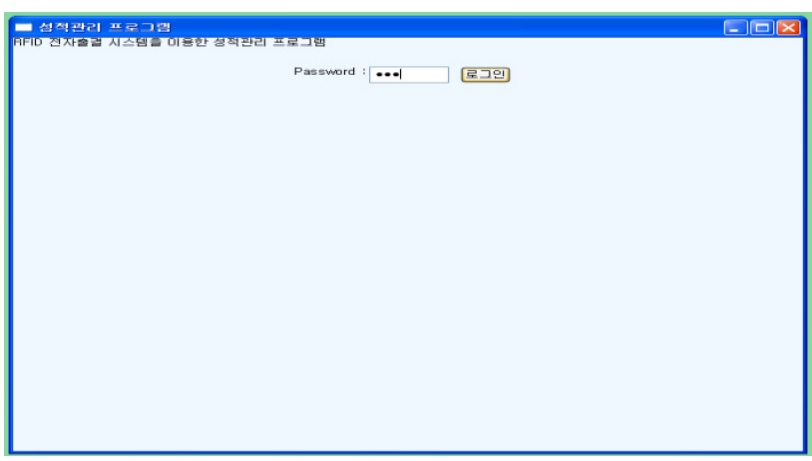

Fig. 7. Log-in Screen of Manager

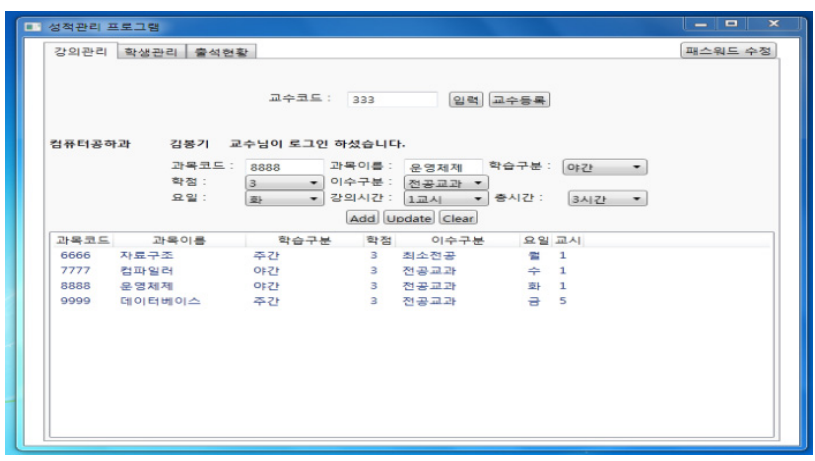

Fig. 8. Class Management of Manager

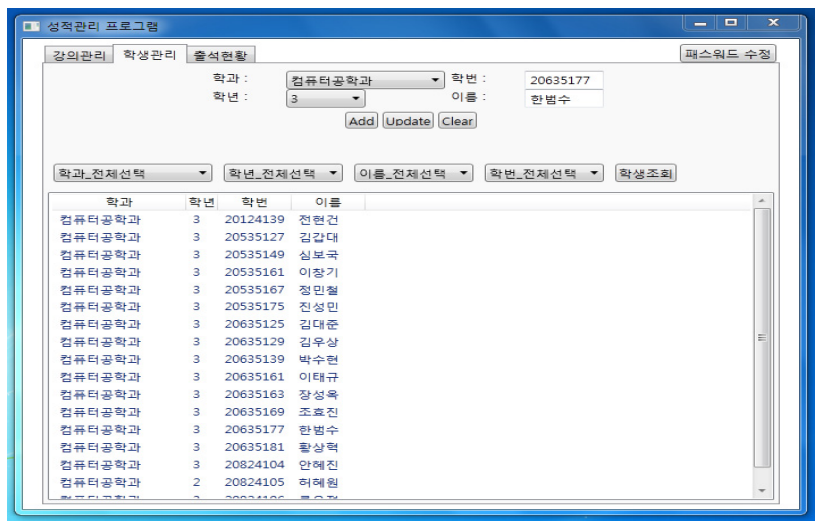

Fig. 9. Student Management

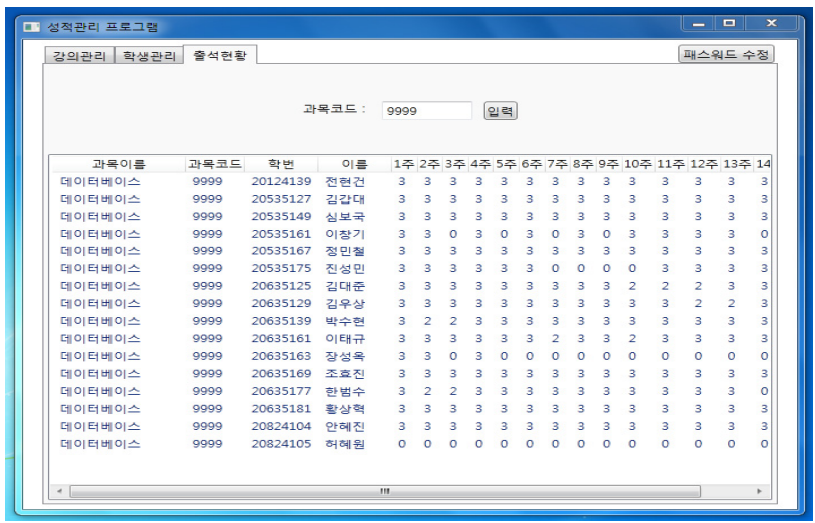

Fig. 10. Attendance Information Identify 


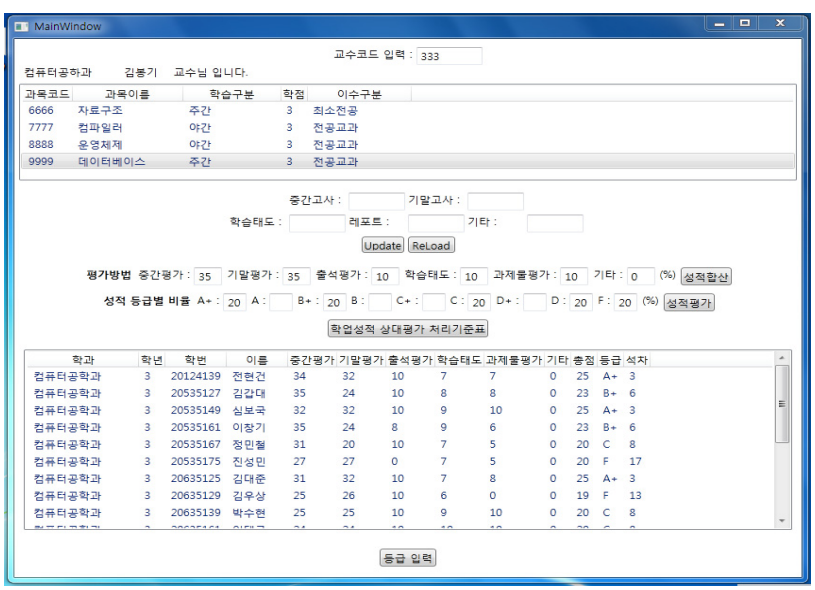

Fig. 11. Record Processing Screen

\section{CONCLUSIONS}

In this study, a recording processing system was implemented using the RFID attendance information. Existing attendance recordation using a paper roster is replaced by an RFID-based system to be applied to a recording processing system.

For efficient management of the experimental equipment and automatic attendance recognition, class attendance recognition was added to the existing student ID, which was already being used for library entrance recognition.

For a better system and realization of a u-Campus, studies on an automatic assignment grading system with a tag attached to paper and automatic grade input are necessary.

\section{ACKNOWLEDGMENT}

This work was supported by Gyeongnam national University of Science and Technology Grant

\section{REFERENCES}

[1] S. C. Kang, H. C. Kim, Y. H. Doh, K. M. Lee and D. H. Kim. "A Study of Gate Control System using RFID," Jurnal of the KAIS, vol. 8, no. 6, pp. 1505-1512, 2007.

[2] Rebecca Angeles(2005), "RFID technologies: supply-chain applications and implementation issues." www.ism.journal.com.

[3] Korea Association of RFID/USN Convergence, RFID GL Technology Certification, YoungJin, Press, 2008.

[4] B. S. Park, "RFID Middleware System based on XML for Processing Large-Scale Data," Jurnal of the KCA vol. 52, no. 3, 2007.

[5] Mi-hye Baek, Design and Implementation of Record Processing System Supporting Automatic Attendance Based on RFID, Master's Thesis of GNTECH, 2010.

[6] Ron Welnstein(2005), "RFID: a technical overview and its application to the enterprise." IT professional. computer.org.
Mi-Hye Baek She received the B.S. and M.S. degrees in computer science \& engineering from Gyeongnam National University of Science and Technology, Korea in 2009, 2011 respectively Her research interests include multimedia system, ubiquitous computing, home networking and mobile system.

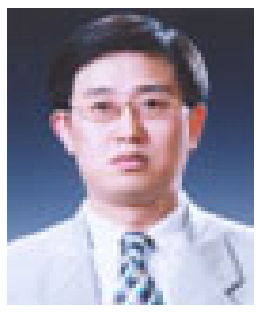

Bong-Gi Kim He received the B.S., M.S., and Ph.D. degrees in computer science from Soongsil University, Korea in 1987, 1989, and 1999 respectively. Since 1999, he has been with Gyeongnam National University of Science and Technology, Korea, where he is currently professor in the Department of Computer Convergence Engineering. His research interests include multimedia system, ubiquitous computing, home networking and mobile system.

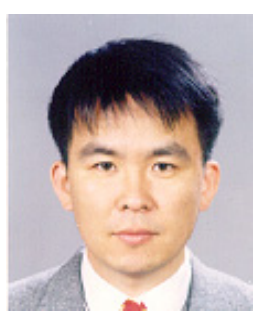

Hyun-Ju Kim He received the B.S., M.S., and Ph.D. degrees in computer science from National Gyeongsang University, Soongsil University Korea in 1988, 1990 and 2000 respectively. Since 2002 he has been with Gyeongnam National University of Science and Technology, Korea, where he is currently associated professor in the Department of Computer Convergence Engineering. His research interests include Information retrieval, XML, Mobile programming. 